\title{
Effect of ultrasonic treatment on the structure and microhardness of ultrafine grained nickel processed by high pressure torsion
}

\author{
A. A. Mukhametgalina ${ }^{1,2}$, A. A. Samigullina ${ }^{1, \uparrow}$, S. N. Sergeyev ${ }^{1}$, A.P. Zhilyaev ${ }^{1}$, \\ A. A. Nazarov ${ }^{1}$, Yu. R. Zagidullina ${ }^{1,3}$, N. Yu. Parkhimovich ${ }^{1}$, V. V. Rubanik ${ }^{4}$, Yu. V. Tsarenko ${ }^{4}$ \\ †asiya_nazarova@mail.ru
}

\author{
${ }^{1}$ Institute for Metals Superplasticity Problems RAS, 39 Khalturin St., 450001, Ufa, Russia \\ ${ }^{2}$ Bashkir State University, 32 Zaki Validi Str., 450076, Ufa, Russia \\ ${ }^{3}$ Ufa State Petroleum Technological University, 14 Pervomayskaya St., 450000, Ufa, Russia \\ ${ }^{4}$ Institute of Technical Acoustics NAS of Belarus, 13 Lyudnikova pr., 210023, Vitebsk, Belarus
}

\begin{abstract}
Effect of ultrasonic treatment (UST) on the microstructure and microhardness of ultrafine grained nickel processed by high pressure torsion (HPT) was studied. With this aim, samples after HPT were subjected to oscillating compression-tension stresses with amplitudes 15,30,45, 60 and $90 \mathrm{MPa}$ in the zone of strain antinode of an ultrasonic instrument. The microstructure of initial and ultrasonically treated samples was studied by X-ray diffraction analysis, transmission electron microscopy and electron back-scatter diffraction (EBSD). Dependences of average dislocation density, internal strains and microhardness on the ultrasound amplitude were obtained. At lower amplitudes (15, 30 MPa) UST leads to some increase of microhardness, internal stresses and dislocation density. At amplitude $60 \mathrm{MPa}$ a considerable reduction of all mentioned characteristics as compared to the initial state occurs, while with a further increase of the amplitude to $90 \mathrm{MPa}$ they exhibit a back increase. An increase of the fraction of high-angle boundaries without a significant change in the average grain size also occurs after UST. The regularities observed are explained as follows. With an increase of ultrasound amplitude, generation and accumulation of dislocations in the grains occur first. Then the processes of their passing through grain boundaries and rearrangement are activated that results in an increase of misorientations of the grains, more effective screening of dislocation stress fields and stress relaxation. With further increase of the stress amplitude processes of generation and accumulation of dislocations prevails over the processes of their annihilation and rearrangement, so that the relaxation effect weakens and diminishes.
\end{abstract}

\section{Влияние ультразвуковой обработки на микроструктуру и микротвердость ультрамелкозернистого никеля, полученного методом кручения под высоким давлением}

\author{
Мухаметгалина А.А. ${ }^{1,2}$, Самигуллина А. А. ${ }^{1, \dagger}$, Сергеев С. Н. ${ }^{1}$, Жиляев А. П. ${ }^{1}$, \\ Назаров А. А. ${ }^{1}$, Загидуллина Ю. Р. ${ }^{1,3}$, Пархимович Н. Ю. ${ }^{1}$, Рубаник В. В. ${ }^{4}$, Царенко Ю. В. ${ }^{4}$ \\ †asiya_nazarova@mail.ru
}

\footnotetext{
${ }^{1}$ Институт проблем сверхпластичности металлов РАН, ул. Ст. Халтурина 39, 450001, Уфа, Россия ${ }^{2}$ Башкирский государственный университет, ул. Заки Валиди 32, 450076, Уфа, Россия

зуфимский государственный нефтяной технический университет, ул. Первомайская 14, 450000, Уфа, Россия

${ }^{4}$ Институт технической акустики НАН Беларуси, пр-т Людникова 13, 210023, Витебск, Беларусь
}

Исследовано влияние ультразвуковой обработки (УЗО) на микроструктуру и микротвердость никеля с ультрамелкозернистой структурой, полученной методом кручения под квазигидростатическим давлением (КГД). Для этого образцы после КГД были подвергнуты знакопеременным напряжениям сжатия-растяжения с амплитудами 15, 30, 45, 60 и 90 МПа в зоне пучности деформаций ультразвукового инструмента. Микроструктура исходных и подвергнутых УЗО образцов исследована методами рентгеноструктурного анализа, просвечивающей электронной микро- 
скопии и дифракции обратно рассеянных электронов (EBSD). Получены зависимости средней плотности дислокаций, величины внутренних напряжений и микротвердости от амплитуды ультразвука. При относительно низких амплитудах (15, 30 МПа) УЗО приводит к некоторому росту микротвердости, внутренних напряжений и плотности дислокаций. При амплитуде 60 МПа происходит заметное снижение всех указанных характеристик по сравнению с исходным состоянием, а при дальнейшем увеличении амплитуды напряжений до 90 МПа - их обратное повышение. При УЗО также происходит увеличение доли большеугловых границ зерен без значительного изменения среднего размера зерна. Обнаруженные закономерности могут быть объяснены следующим образом. С повышением амплитуды ультразвука сначала происходит зарождение и накопление дислокаций в зернах. Затем активизируются процессы их прохождения через границы зерен и перестройки, что приводит к увеличению взаимной разориентации зерен, к наибольшей экранировке полей напряжений дислокаций и релаксации напряжений. При дальнейшем увеличении амплитуды напряжений процессы генерации и накопления дислокаций преобладают над процессами их аннигиляции и перестройки, вследствие чего эффект релаксации ослабевает и исчезает.

Ключевые слова: ультразвуковая обработка, ультрамелкозернистые материалы, кручение под высоким давлением, микроструктура.

\section{1. Введение}

С целью улучшения эксплуатационных свойств материалов в материаловедении используются различные способы физического воздействия, направленные на изменение их структуры. Одним из таких способов является ультразвуковая обработка (УЗО), то есть, колебательное механическое воздействие с частотой, соответствующей ультразвуковому диапазону (как правило, вблизи 20 кГц).

Широко известны, например, методы упрочнения кристаллических материалов путем поверхностной обработки ультразвуком $[1,2]$. Другим примером является повышение пластичности материалов при их деформировании с наложением высокочастотных колебаний, что позволяет значительно снизить требуемые усилия и энергозатраты в процессе обработки металлов давлением, в частности, в условиях сверхпластической деформации [3]. С помощью ультразвука также возможно ускорение некоторых процессов в металлах, например, фазовых превращений [4] и эффекта памяти формы в сплавах $\mathrm{Ti}-\mathrm{Ni}[5]$.

В настоящее время возрос интерес к исследованиям влияния УЗО на структуру и свойства перспективных материалов, в числе которых особое место занимают ультрамелкозернистые (УМЗ) и наноструктурные металлы и сплавы, полученные методами интенсивной пластической деформации (ИПД). Помимо высоких прочностных характеристик, такие материалы характеризуются значительным уровнем внутренних напряжений, микроискажений решетки, высокой плотностью дефектов, что приводит к снижению их пластичности, термической стабильности микроструктуры и механических свойств [6, 7].

Ультразвуковые колебания воздействуют на дефектную структуру материала, способствуя перемещению, взаимодействию и аннигиляции дислокаций [8 - 10], стимулируя процессы полигонизации и возврата, что приводит к усовершенствованию его микроструктуры [10, 11]. Такое воздействие колебаний приводит к ускорению процесса релаксации остаточных напряжений и связанным с ним изменениям механических свойств.

Несмотря на проведенные к настоящему времени исследования в этом направлении, множество вопро- сов о механизмах воздействия ультразвука на структуру УМЗ материалов, а также зависимости их свойств от различных параметров УЗО остаются открытыми и требуют дальнейшего изучения.

Ранее в работе [12] авторами было показано, что в результате УЗО в никеле, подвергнутом кручению под высоким давлением, происходит снижение внутренних напряжений, и может увеличиваться термическая стабильность его структуры. В работах $[13,14]$ была исследована зависимость механических свойств никеля, подвергнутого равноканальному угловому прессованию, от амплитуды ультразвука. Было показано, что эта зависимость является немонотонной, и существует оптимальное значение амплитуды ультразвука, при котором и предел прочности, и удлинение до разрушения достигают максимума.

В настоящей работе проводилось исследование влияния УЗО с различными амплитудами напряжений на микроструктуру и микротвердость УМЗ никеля, полученного методом кручения под высоким давлением, с целью выяснения механизмов воздействия ультразвука на дефектную структуру материалов.

\section{2. Материалы и методика проведения эксперимента}

В качестве исходного материала для исследований были использованы образцы технически чистого (99,5\%) никеля марки НП-2 в виде дисков толщиной 1 мм и диаметром 10 мм, которые были подвергнуты интенсивной пластической деформации кручением под квазигидростатическим давлением (КГД) 6 ГПа на наковальнях Бриджмена при комнатной температуре. В результате кручения были получены образцы толщиной 0,35 мм и диаметром 11 мм, имеющие УМЗ структуру со средним размером зерен около 300 нм. Ультразвуковая обработка осуществлялась по схеме, приведенной на рис. 1. Ультразвуковой преобразователь 2, питающийся от генератора 1, возбуждает в полуволновом концентраторе 3 стоячую волну, которая имеет пучность напряжений в месте расположения образца 4. Образец с помощью прижимного цилиндра 5, имеющего резьбу, плотно зажат внутри концентратора и таким образом составляет часть колебательной системы. Путем изме- 
нения подводимой к преобразователю мощности на образце были возбуждены осциллирующие напряжения сжатия-растяжения, амплитуды которых составляли приблизительно 15, 30, 45, 60 и 90 МПа.

Как для исходного УМЗ состояния, так и после каждого режима УЗО были проведены измерения микротвердости и исследована микроструктура образцов с использованием методик EBSD-анализа, рентгеноструктурного анализа (PCA) и просвечивающей электронной микроскопии (ПЭМ).

Величины внутренних напряжений и размеры областей когерентного рассеяния (ОКР) определяли по данным РСА, полученным на дифрактометре ДРОН-4. Образцы подвергали механической, а затем электролитической полировке для снятия наклепанного поверхностного слоя. Съемка проводилась с шагом $0,05^{\circ}$ и временем экспозиции 4 с. Использовали $\mathrm{CuK}_{\alpha}$ излучение с фокусировкой по Бреггу-Брентано со щелями Соллера на первичном пучке и графитовым кристалл-монохроматором на дифрагированном пучке. Обработка экспериментальных данных осуществлялась с использованием программы X-RAY.

Микроструктуру исследовали методом ПЭМ на микроскопе JEM 2000ЕХ. Фольги для электронномикроскопических исследований готовили стандартными методами на приборе для струйной полировки TenuPOL (Struers).

EBSD-анализ проводился с помощью микроскопа TESCAN MIRA 3 LMH FEG с приставкой для EBSD-анализа «CHANNEL 5». Съемку осуществляли в пошаговом режиме с шагом 100, 50 и 35 нм с площади соответственно 400, 100 и 25 мкм². Поверхность образцов для съемки готовилась с помощью электролитической полировки.

Измерения микротвердости по Виккерсу проводили на установке Axiovert100A с приставкой МНТ-10 при нагрузке индентора 100 г и времени выдержки 10 c.

\section{3. Результаты эксперимента и обсуждение}

На рис. 2 представлены фотографии микроструктуры никеля во всех шести состояниях. Как видно из фотографий, во всех случаях наблюдается практически равноосная УМЗ структура. Состояния, полученные УЗО со значениями амплитуды 15, 30 и 45 МПа, как и необ-

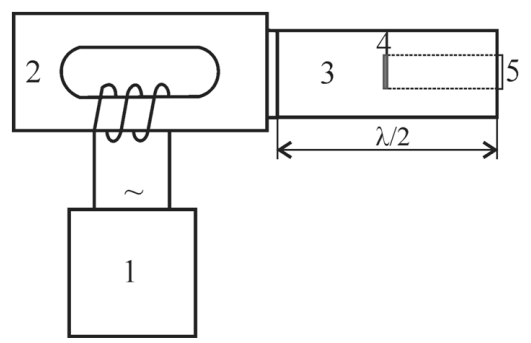

Рис. 1. Принципиальная схема ультразвуковой обработки: 1 - ультразвуковой генератор; 2 - преобразователь; 3 - концентратор; 4 - образец, 5 - прижимной цилиндр.

Fig. 1. Schematic diagram of the ultrasonic treatment: 1 - ultrasonic generator; 2 - transducer; 3 - concentrator; 4 - sample, 5 - clamping cylinder. работанное ультразвуком состояние, характеризуются значительным изменением контраста в теле зерен и субструктурой, а также неровными, размытыми границами зерен (рис. 2a-d). Микроструктура после УЗО с амплитудами 60 и 90 МПа подобна структуре после отжига: становится заметным характерный полосовой контраст вблизи границ зерен, внутренние объемы зерен имеют заметно меньшее изменение контраста, а углы на тройных стыках границ зерен становятся близкими к $120^{\circ}$.

Во всех шести состояниях на картинах микродифракции, снятых с площади 0,5 мкм², присутствует большое число рефлексов, расположенных по окружности и испытывающих азимутальное размытие, что свидетельствует о наличии большого числа зерен на данной площади и о внутренних напряжениях, создаваемых неравновесными границами зерен.

Зависимость микротвердости никеля от амплитуды УЗО показана на рис. 3. Измерение проводили в центральной части образца и на расстоянии от центра, равном половине радиуса образца.

После УЗО с небольшой амплитудой напряжений происходит некоторое увеличение микротвердости по сравнению с исходным деформированным состоянием. Однако с увеличением амплитуды ее значение снижается, и в состоянии, соответствующем амплитуде 60 МПа, достигает минимума. При дальнейшем увеличении амплитуды ультразвука до 90 МПа микротвердость вновь увеличивается.

Аналогичная тенденция наблюдается и на графике зависимости среднеквадратической микродеформации, рассчитанной из данных PCA (рис. 4), от амплитуды УЗО. Наименьшее значение микродеформации наблюдается в состоянии после обработки с амплитудой $60 \mathrm{MПа,}$ после чего оно увеличивается до уровня, соответствующего деформированному состоянию. При этом размеры ОКР значительно не меняются.
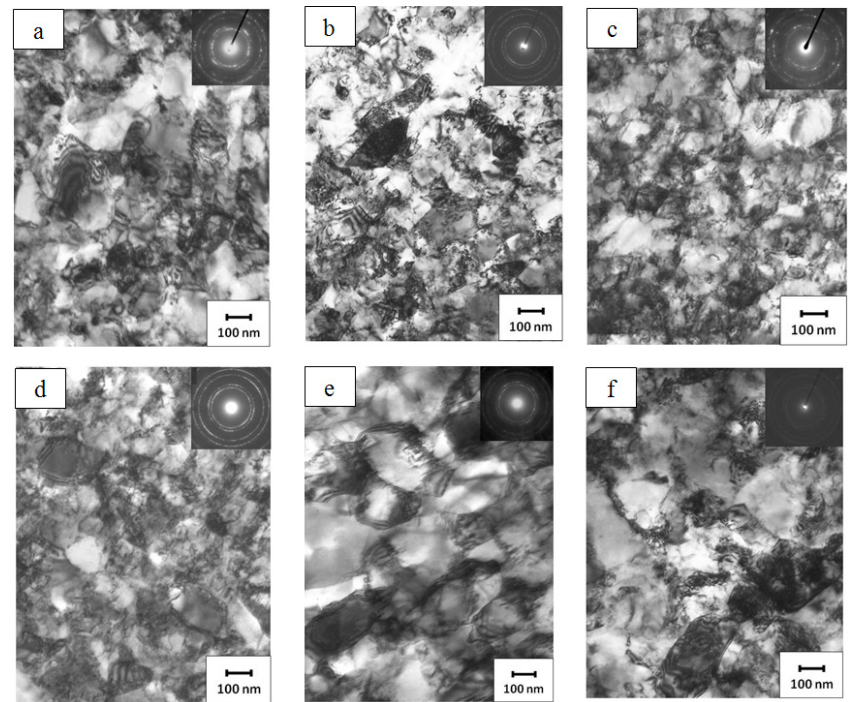

Рис. 2. Микроструктура никеля после КГД (а) и последующей ультразвуковой обработки с амплитудами 15 (b), 30 (c), 45 (d), 60 (e), 90 (f) МПа.

Fig. 2. Microstructure of nickel after HPT (a) and subsequent ultrasonic treatment with amplitudes of 15 (b), 30 (c), 45 (d), 60 (e), 90 (f) $\mathrm{MPa}$. 
По данным EBSD-анализа был построен график зависимости плотности дислокаций и среднего диаметра зерен от амплитуды ультразвука для области, расположенной на расстоянии половины радиуса от центра образца (рис. 5). Как видно, эта зависимость кореллирует с данными РСА, и наименьшая плотность дислокаций наблюдается в точке, соответствующей режиму УЗО с амплитудой 60 МПа. При этом средний диаметр зерен значительно не меняется.

Соотнесем наиболее характерные точки представленных зависимостей с микроструктурой соответствующих им состояний. Рассмотрим более детально микроструктуру образцов после КГД и после трех режимов У3О: с наименьшей амплитудой 15 МПа; с амплитудой 60 МПа, соответствующей минимальным значениям микротвердости, среднеквадратической микродеформации и плотности дислокаций; с наибольшей амплитудой напряжения $90 \mathrm{MПа} \mathrm{(рис.} \mathrm{6).}$

Образец УМЗ никеля после КгД имеет характерную для деформированного состояния высокодефектную внутризеренную структуру с неравновесными грани-

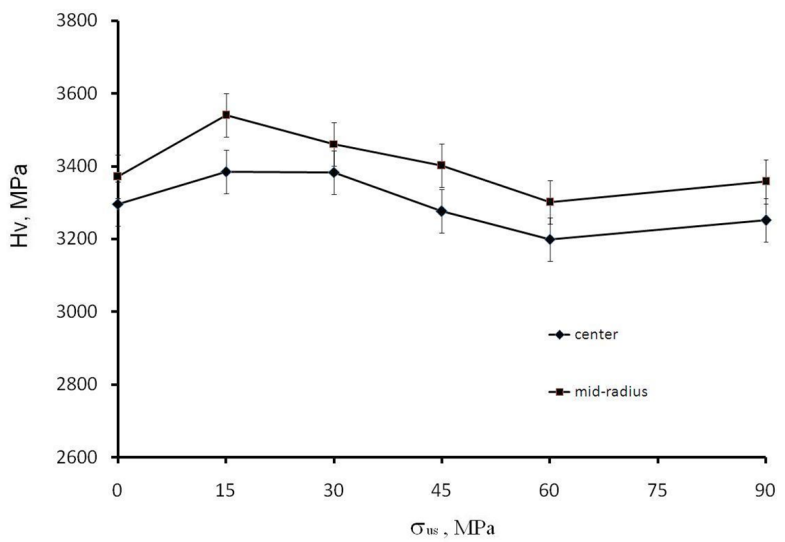

Рис. 3. Зависимость микротвердости никеля, подвергнутого КГД, от амплитуды УЗО. Графики представлены для центральной части образца и для точек, находящихся от центра на расстоянии, равном половине радиуса образца.

Fig.3. The dependence of microhardness of nickel subjected to HPT on the UST amplitude. Plots are presented for the central part of the sample and for the points located at a distance from the center equal to half a radius of the sample.

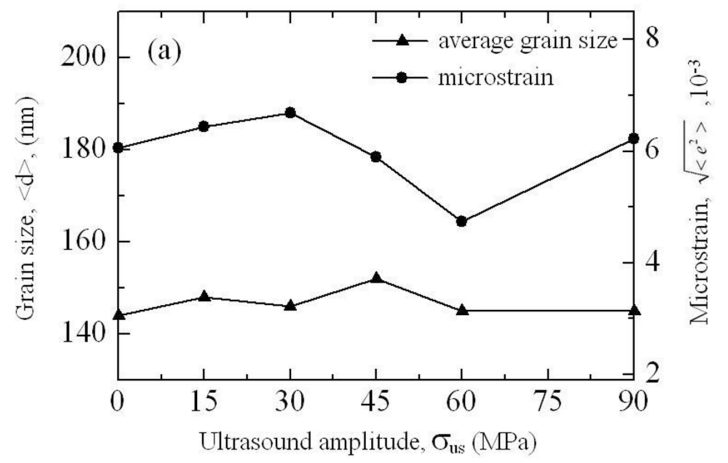

Рис. 4. Зависимость среднеквадратической микродеформации и размера ОКР от амплитуды УЗО для никеля после КГД.

Fig. 4. The dependence of the mean squared microstrain and CSD size on the UST amplitude for nickel after HPT. цами зерен, проявляющимися на ПЭМ-изображениях в виде полос экстинкции (рис. 6а). В образце никеля, подвергнутом УЗО с амплитудой 15 МПа, также наблюдается большое число дислокационных групп, особенно вблизи границ зерен (рис. 6b). По-видимому, под воздействием ультразвука с небольшой амплитудой происходит их генерация и накопление внутри зерен, с чем и связано повышение микротвердости, внутренних напряжений и плотности дислокаций, рассчитанных по данным PCA и EBSD-анализа. При этом напряжения еще недостаточны для того, чтобы дислокации входили в границы зерен, проходили через них, поэтому возможности их аннигиляции ограничены.

В состоянии, полученном путем воздействия ультразвуком с амплитудой 60 МПа, микроструктура представлена практически бездефектными зернами, а также четкими ровными границами зерен (рис. 6с). Воздействие ультразвука данной амплитуды, по-видимому, достаточно, чтобы способствовать прохождению дислокаций через границы, более глобальным перестройкам дислокационных систем, превращению малоугловых границ

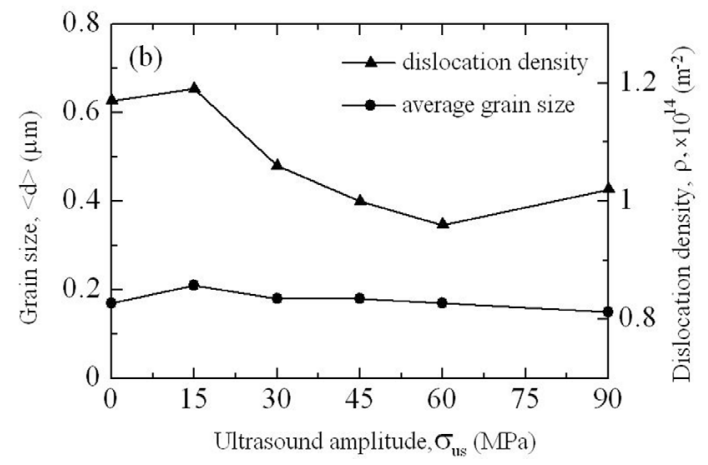

Рис. 5. Зависимость плотности дислокаций и среднего размера зерна, рассчитанных по данным EBSD-анализа, от амплитуды УЗО для никеля после КГД.

Fig. 5. The dependence of dislocation density and the average grain size calculated from the EBSD-analysis data on the UST amplitude for nickel after HPT.
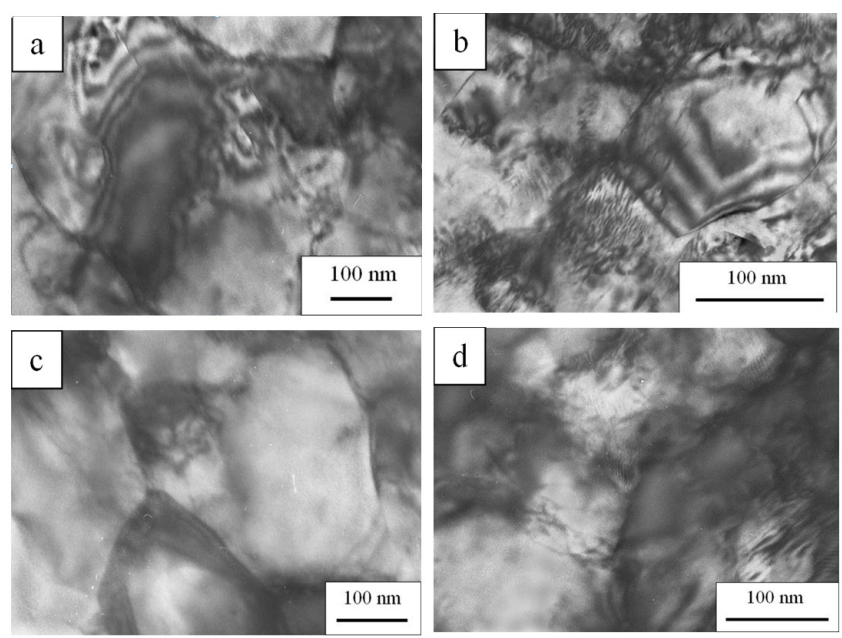

Рис. 6. Дефектная структура никеля после КГД (а) и УЗО с амплитудами 15 (b), 60 (c), $90 \mathrm{MПа} \mathrm{(d).}$

Fig. 6. The defect structure of nickel after HPT (a) and ultrasonic treatment with amplitudes of 15 (b), 60 (c), 90 (d) MPa. 
в большеугловые путем их слияния и т.д., что приводит к большей экранировке полей напряжений дислокаций и релаксации напряжений.

В состоянии после УЗО с наибольшей из исследованных амплитуд, во всей видимости, интенсивность генерации дислокаций уже настолько высока, что рост плотности дефектов преобладает над процессами их перестройки и аннигиляции. Поэтому увеличивается плотность дислокаций внутри зерен, что видно на рис. $6 \mathrm{~d}$ и на графике зависимости плотности дислокаций от амплитуды УЗО (рис. 4).

Для анализа изменения текстуры при УЗО были построены обратные полюсные фигуры (рис. 7). В исходном деформированном образце можно выделить две области с определёнными преимущественными кристаллическими направлениями. Однако с увеличением амплитуды УЗО одна из компонент текстуры ослабевает и в состоянии, соответствующем УЗО с амплитудой 60 МПа, полностью исчезает. Это можно объяснить тем, что генерируемые при УЗО дислокации, встраиваясь в границы зерен, увеличивают их взаимную разориентацию и приводят к повороту зерен.

Вклад дислокаций в увеличение разориентаций зерен подтверждается и распределением границ зерен по углам разориентации для всех шести состояний, представленным в таблице 1. Границы зерен объединены в три большие группы: малоугловые (МУГ, от $2^{\circ}$ до $15^{\circ}$ ), большеугловые (БУГ, выше $15^{\circ}$ ) и границы, близкие к специальным. В состоянии, соответствующем режиму У3О с амплитудой 60 МПа, наблюдается наименьшая доля малоугловых и соответственно наибольшая доля большеугловых границ зерен.

\section{4. Заключение}

Таким образом, УЗО значительно влияет на микроструктуру и микротвердость никеля с УМЗ структурой, полученной кручением под высоким давлением.
При этом эффект зависит от амплитуды ультразвука. Среди исследованных состояний, состояние, полученное воздействием ультразвука с амплитудой напряжений $60 \mathrm{MПа,} \mathrm{демонстрирует} \mathrm{наибольший} \mathrm{эффект} \mathrm{ре-}$ лаксации структуры, в результате которой происходит снижение доли малоугловых границ и увеличение доли большеугловых границ зерен, снижение плотности дис-

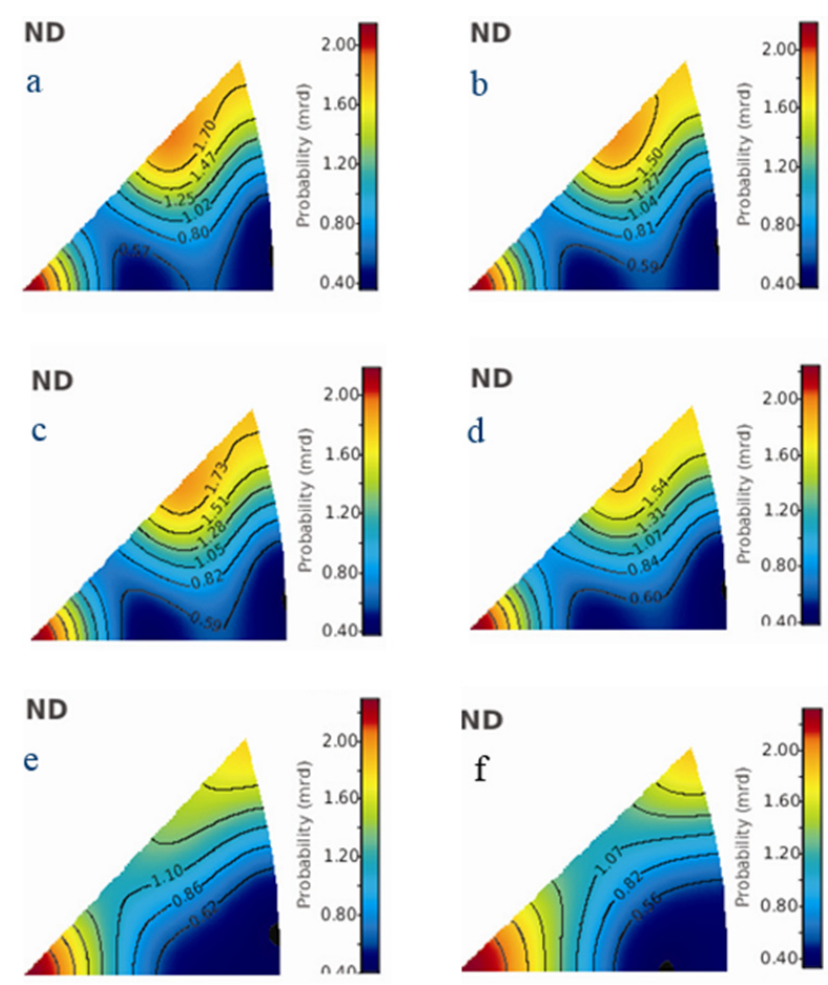

Pис. 7. (Color online) Обратные полюсные фигуры для образцов никеля после КГД (а) и УЗО с амплитудами 15 (b), 30 (c), 45 (d), 60 (e), 90 (f) МПа.

Fig. 7. (Color online) The inverse pole figures of nickel after HPT (a) and ultrasonic treatment with amplitudes of 15 (b), 30 (c), 45 (d), 60 (e), 90 (f) MPa.

Табл. 1. Распределение границ зерен по углам разориентации для никеля, подвергнутого КГД и УЗО с различными амплитудами. Table 1. Distribution of grain boundaries by misorientation angles for nickel subjected to HPT and UST of different amplitudes.

\begin{tabular}{|c|c|c|c|}
\hline $\begin{array}{l}\text { Состояние } \\
\text { State }\end{array}$ & $\begin{array}{c}\text { МУГ }\left(2^{\circ}-15^{\circ}\right), \% \\
\text { Low angle } \\
\text { boundaries } \\
\left(2^{\circ}-15^{\circ}\right), \%\end{array}$ & $\begin{array}{c}\text { Границы, близкие к специальным, \% } \\
\text { Boundaries close to special, \% }\end{array}$ & $\begin{array}{c}\text { БУГ }\left(>15^{\circ}\right), \% \\
\text { High angle } \\
\text { boundaries } \\
\left(>15^{\circ}\right), \%\end{array}$ \\
\hline $\begin{array}{l}\text { КГД } \\
\text { НРТ }\end{array}$ & 25 & 9 & 66 \\
\hline $\begin{array}{l}\text { КГД+УЗО } 15 \mathrm{MПа} \\
\text { НРТ+UST } 15 \mathrm{MPa}\end{array}$ & 22 & 9 & 69 \\
\hline $\begin{array}{l}\text { КГД+УЗО } 30 \mathrm{MПа} \\
\text { НРТ+UST } 30 \mathrm{MPa}\end{array}$ & 20 & 9 & 71 \\
\hline $\begin{array}{l}\text { КГД+УЗО } 45 \mathrm{MПа} \\
\text { НРТ+UST } 45 \mathrm{MPa}\end{array}$ & 20 & 9 & 71 \\
\hline $\begin{array}{l}\text { КГД+УЗО } 60 \mathrm{MПа} \\
\text { НPT+UST } 60 \mathrm{MPa}\end{array}$ & 17 & 10 & 73 \\
\hline $\begin{array}{l}\text { КГД+УЗО } 90 \mathrm{MПа} \\
\text { НРТ+UST } 90 \mathrm{MPa}\end{array}$ & 19 & 10 & 71 \\
\hline
\end{tabular}


локаций, а также релаксация границ зерен и тройных стыков из неравновесного состояния к равновесному без значительного увеличения среднего размера зерен. При увеличении амплитуды УЗО выше этого значения процессы размножения дислокаций постепенно преобладают над процессами их аннигиляции и перестройки в БУГ, вследствие чего эффект релаксации ослабевает, и начинается процесс упрочнения.

Благодарность/Acknowledgements. Настоящзая работа была поддержана Российским научным бондом (грант № 16-19-10126). The present work was supported by the Russian Science Foundation (grant No 16-19-10126).

\section{Литература/References}

1. Yu. R. Kolobov, O. A. Kashin, E. F. Dudarev et al. Russian Phys. J. 43 (9), 754 (2000) (in Russian). [Ю. Р. Колобов, О.А. Кашин, Е.Ф. Дударев и др. Изв. вузов. Физика. 9, 45 (2000)].

2. A. V. Panin, E. A. Melnikova, O. B. Perevalova, et al. Fiz. mezomekh 12 (1), 83 (2009) (in Russian). [А. В. Панин, Е. А. Мельникова, О.Б. Перевалова и др. Физ. мезоMex. 12 (1), 83 (2009)].

3. M. M. Myshlyaev, V. V. Shpeizman, V. V. Klubovich et al. Phys. Solid State 57 (10), 2039 (2015). [M. М. Мышляев, В.В. Шпейзман, В.В. Клубович и др. ФТТ, 57 (10), 1986 (2015)].

4. Y. Han, Ke Li, J. Wang et al. Mater. Sci. Eng. A 405 (1-2), 306 (2005).

5. V. V. Rubanik Jr., V. V. Rubanik, V.V. Klubovich. Mater. Sci. Eng. A 481 -482, 620 (2008).

6. A.A. Nazarov, R.R. Mulyukov. In: Handbook of Nanoscience, Engineering, and Technology, Ed. W. Goddard, D. Brenner, S. Lyshevski, G. Iafrate, CRC Press. 2003, p. $22-1$.

7. R.Z. Valiev, A.P. Zhilyaev, T.G. Langdon. Bulk Nanostructured Materials: Fundamentals and Applications. Hoboken, Wiley. (2013) 440 p.

8. N.A. Tyapunina, V. V. Blagoveschenskiy, G. M.Zinenkova, Yu. A. Ivashkin. Inzestiya Vuzov. Fizika 6, 118 (1982) (in Russian). [Н.А. Тяпунина, В.В. Благовещенский, Г.М. Зиненкова, Ю.А. Ивашкин. Изв. вузов. Физика. 6, 118 (1982)].

9. S. V. Dmitriev, A.I. Pshenichnyuk, A. M. Iskandarov, A. A. Nazarova. Modelling Simul. Mater. Sci. Eng. 18, 025012 (2010).

10. D. V. Bachurin, R.T. Murzaev, Yu.A. Baimova, A. A. Samigullina, K. A. Krylova. Letters on Materials 6, 183 (2016) (in Russian). [Д. В. Бачурин, Р. Т. Мурзаев, Ю.А. Баимова, А.А. Самигуллина, К.А. Крылова. Письма о материалах 6,183 (2016)].

11. A. A. Nazarov, Sh. Kh. Khannanov. Fizika i khimiya obrabotki materialov 4, 109 (1986) (in Russian). [А.А. Назаров, Ш.Х. Ханнанов. Физ. химия обр. матер. 4, 109 (1986)].

12. A. A. Nazarova, R. R. Mulyukov, V. V. Rubanik et al. Phys. Metals Metallogr. 110 (6), 574 (2010). [А. А. Назарова, Р.Р. Мулюков, В.В. Рубаник и др. ФММ, 110 (6), 600 (2010)].

13. A. A. Samigullina, Yu. V. Tsarenko, V. V. Rubanik, et al. Letters on Materials 2, 214 (2012). [А.А. Самигуллина, Ю. В. Царенко, В.В. Рубаник и др. Письма о материалах 2, 214 (2012)].

14. A. A. Samigullina, A.A. Nazarov, R. R. Mulyukov et al. Rev. Adv. Mater. Sci. 39, 48 (2014). 